\title{
Assessing the Longitudinal Impact of Physician- Patient Relationship on Functional Health
}

R. Henry Olaisen, $M P H, P b D^{1,3}$

Mark D. Scblucbter, $P b D^{1}$

Susan A. Flocke, $M A, P b D^{2}$

Katbleen A. Smyth, $P b D^{1}$

Siran M. Koroukian, MHA, $P b D^{1}$

Kurt C. Stange, $M D, P b D^{1,3}$

'Department of Population and Quantitative Health Sciences, Case Western Reserve University, Cleveland, Ohio

${ }^{2}$ Department of Family Medicine, Oregon Health \& Science University, Portland,

Oregon

${ }^{3}$ Center for Community Health Integration, Departments of Family Medicine \& Community Health, Population and Quantitative Health Sciences, Sociology, and the Case Comprehensive Cancer Center, Case Western Reserve University, Cleveland, Ohio

Conflicts of interest: S.M.K. is a site PI on a grant funded by Celgene Corporation. Other authors report none.

\section{CORRESPONDING AUTHOR}

R. Henry Olaisen, MPH, PhD

Center for Community Health Integration 11000 Cedar Ave, Ste 402

Cleveland, $\mathrm{OH} 44106$

rho2@case.edu

\begin{abstract}
PURPOSE Access to a usual source of care is associated with improved health outcomes, but research on how the physician-patient relationship affects a patient's health, particularly long-term, is limited. The aim of this study was to investigate the longitudinal effect of changes in the physician-patient relationship on functional health.
\end{abstract}

METHODS We conducted a prospective cohort study using the Medical Expenditure Panel Survey (MEPS, 2015-2016). The outcome was 1-year change in functional health (12-Item Short-Form Survey). The predictors were quality of physician-patient relationship, and changes in this relationship, operationalized with the MEPS Primary Care (MEPS-PC) Relationship subscale, a composite measure with preliminary evidence of reliability and validity. Confounders included age, sex, race/ethnicity, educational attainment, insurance status, US region, and multimorbidity. We conducted analyses with survey-weighted, covariateadjusted, predicted marginal means, used to calculate Cohen effect estimates. We tested differences in trajectories with multiple pairwise comparisons with Tukey contrasts.

RESULTS Improved physician-patient relationships were associated with improved functional health, whereas worsened physician-patient relationships were associated with worsened functional health, with 1-year effect estimates ranging from $0.05(95 \% \mathrm{Cl}, 0-0.10)$ to $0.08(95 \% \mathrm{Cl}, 0.02-0.13)$ compared with $-0.16(95 \%$ $\mathrm{Cl},-0.35$ to -0.03$)$ to $-0.33(95 \% \mathrm{Cl},-0.47$ to -0.02$)$, respectively.

CONCLUSION The quality of the physician-patient relationship is positively associated with functional health. These findings could inform health care strategies and health policy aimed at improving patient-centered health outcomes.

Ann Fam Med 2020;18:422-429. https://doi.org/10.1370/afm.2554.

\section{INTRODUCTION}

$\mathrm{E}$ cologic studies have shown that primary care is associated with better health, improved health care quality, improved access, and lower cost - virtually the definition of value. ${ }^{1-4}$ Having a usual source of care, defined as access to a regular facility or primary care provider when one is sick or needs medical advice, has been associated with improved health outcomes. ${ }^{5,6}$ Whereas consistent access to a provider is important, the quality of each clinical encounter is equally important in shaping a patient's experience and overall health outcomes. Specifically, the quality of the physician-patient relationship warrants closer research. The physician-patient relationship is a valued primary care process on which other primary care processes depend. ${ }^{7-10}$ A strong physician-patient relationship involves good interpersonal communication, the development of a shared understanding that allows for reliance and trust, and ease of obtaining care, facilitated by the physician serving as a patient advocate. ${ }^{11,12}$

Despite these promising findings, we currently do not fully understand the underlying processes by which primary care exerts its beneficial effects. ${ }^{13,14}$ Moreover, whereas the quality of the physician-patient relationship is a known mechanism for improving patient outcomes, ${ }_{1}^{15-17}$ 
studies have not yet clarified how changes in this fundamental relationship over time affect functional health outcomes.

Primary care research poses challenges, in part due to a shortage of robust measurements capturing unique primary care processes thought to benefit patients. ${ }^{13,15}$ Efforts to elucidate the protective effect of primary care found that ecologic studies using individual-level data showed mixed results. Robust pragmatic trials aimed at improving functional health outcomes among patients with multimorbidity—a high-risk, high-cost, high-priority primary care population-also showed mixed results. ${ }^{16}$ Well-designed cohort studies have the potential to provide empirical evidence at a fraction of the cost of randomized trials by tapping readily available, nationally representative data to guide decision making. Whereas reliable physician-patient relationship instruments exist ${ }_{1}^{18-21}$ until recently no such measure had been specified using the nationally representative Medical Expenditure Panel Survey (MEPS), which provides a rich array of process and outcome data for health services research. ${ }^{22}$

We recently identified, specified, and validated the primary care composite measure (MEPS-PC) — comprising 3 subscales, each capturing distinct primary care processes-using items from MEPS. ${ }^{23,24}$ The availability of this measure has made possible the present study and might also inform future research in this critical area of health care inquiry. The aim of this observational study was to investigate the longitudinal effect of changes in the physician-patient relationship on functional health.

\section{METHODS}

\section{Data}

This observational study relied on secondary data from MEPS. We used the publicly available 2015-2016 Household Component (HC-193) and baseline (2015) Medical Conditions (HC-190) files, both of which can be downloaded at no cost from the Agency for Healthcare Research and Quality's website. ${ }^{25}$ The MEPS Household Component collects data from a sample of families and individuals in selected communities across the United States; this sample is drawn from a nationally representative subsample of households that participated in the prior year's National Health Interview Survey. Data are collected at 5 time points over a 2-year period. This study was guided by the Strengthening the Reporting of Observational Studies in Epidemiology (STROBE) guidelines and checklist for reports of observational studies ${ }^{26}$ and was deemed exempt by the Case Western Reserve University Institutional Review Board (IRB-2016-1682).

\section{Study Design}

We constructed a prospective observational cohort with 2 years of follow-up comprising adults who were $\geq 18$ years of age at the time of the first MEPS interview, had made $\geq 1$ office-based physician visit in both 2015 and 2016, had not died during follow-up, and whose files contained complete data on the outcome as well as, at minimum, a $50 \%$ complete response on items comprising MEPS-PC scores (Figure 1).

\section{Conceptual Model}

This study was guided by a conceptual model in which we hypothesize that the longitudinal trajectory of the physician-patient relationship will affect functional health outcomes. As shown in the directed acyclic graph (Figure 2), ${ }^{27}$ the quality of the physician-patient relationship lies on the causal pathway between usual source of care and health outcomes.

\section{Outcome}

The outcome was overall functional health operationalized with the 12-Item Short-Form Survey (SF-12). ${ }^{28}$ Responses to the SF-12 in MEPS are captured via a mail-in questionnaire, administered twice, approximately 1 year apart. ${ }^{29}$

\section{Predictor}

Physician-patient relationship was operationalized with the MEPS-PC Relationship composite subscale, which has demonstrated preliminary evidence of reliability and validity in published work. ${ }^{23,24}$ The MEPSPC comprises 3 composite subscales, identified via a primary care scoping review and specified with variable reduction techniques. Guided by 16 established primary care processes, we found 32 candidate items in MEPS that are valued in primary care. These items are quality indicators verified as important by an advisory group of primary care subject matter experts. We split our data into a training sample and a testing sample (50-50). Factor analysis of our training data set yielded 3 unique factors involving 24 items. The MEPS-PC Relationship subscale comprises 14 items (Supplemental Appendix 1, https://www.AnnFamMed. org/content/18/5/422/suppl/DC1/) including questions such as, "How often did doctors or other health providers listen carefully to you?" and "How often did doctors or other health providers explain things in a way that was easy to understand?" All 14 questions are scored on a 4 -point ordinal scale. The composite measure shows an internal consistency reliability of 0.86 , with reproducible results in the testing data (Cronbach $\alpha=0.85,3$ factors with equivalent loadings). ${ }^{24}$ This continuous measure displays construct validity against the following 3 known measures of primary 
care: usual source of care, known provider, and family usual source of care. ${ }^{25}$

To analyze the longitudinal effect of changes in the physician-patient relationship on functional health, we constructed longitudinal trajectories using a 2-step

\section{Figure 1. Construction of a prospective cohort study of US adults who had office-based physician visits in 2 consecutive years. Data from MEPS, 2015-2016.}

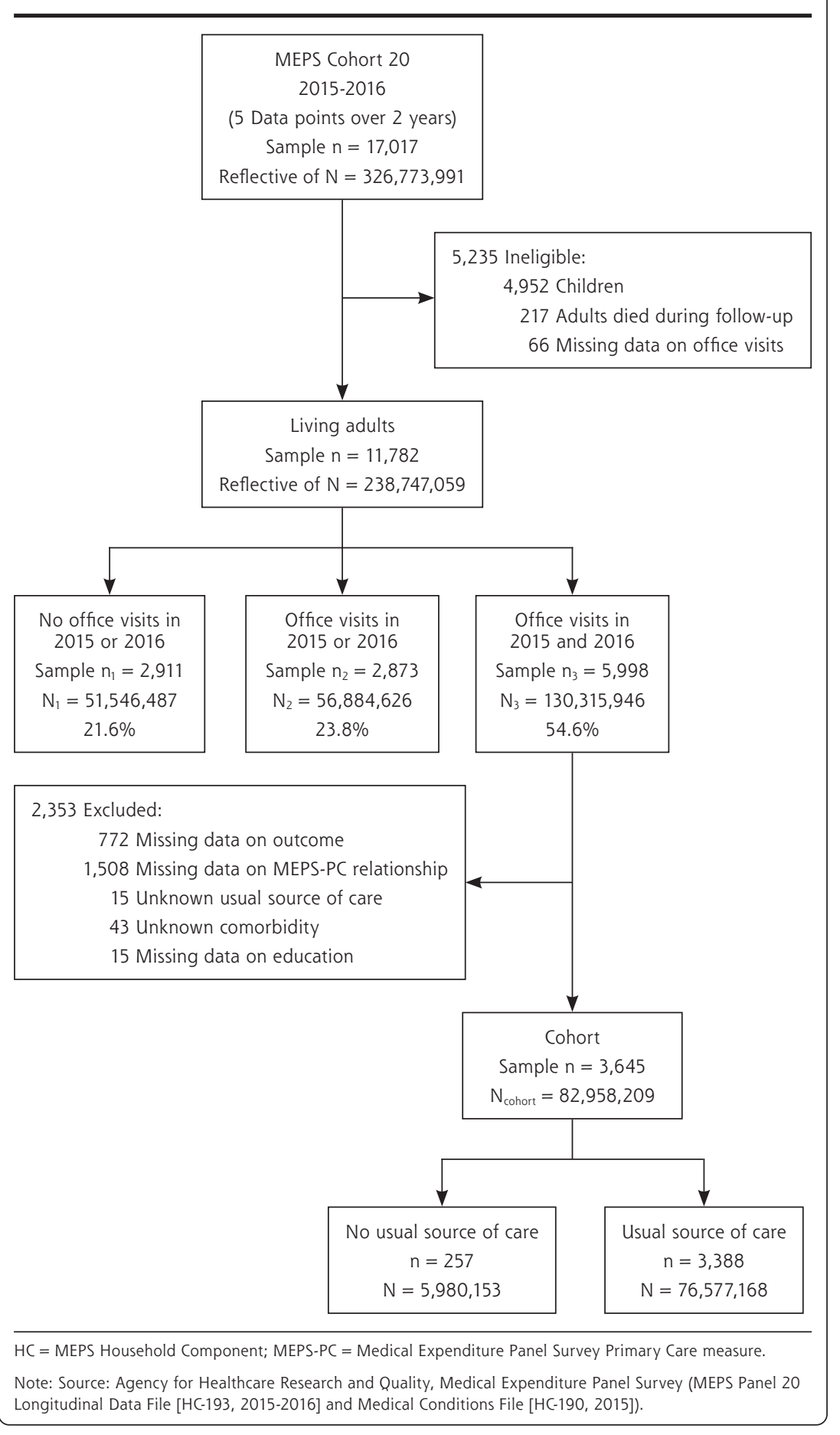

analytic process. First, participants were classified at baseline to 1 of 2 categories, low or high, depending on whether the individual's baseline physician-patient relationship score was greater than or less than the population median score. Depending on whether the individual's follow-up score changed \pm 0.5 SD compared with their baseline score, ${ }^{30}$ they were then conditionally assigned to 1 of 3 possible follow-up trajectories (same, worse, better) (Supplemental Figure 1, https://www.AnnFamMed.org/ content/18/5/422/suppl/DC1/).

\section{Confounders}

Adjustment covariates included age, sex, race/ethnicity, educational attainment, insurance status, multimorbidity, and US region, each represented as categoric variables. The multimorbidity profile was calculated with Clinical Classifications Software (Agency for Healthcare Research and Quality, Healthcare Cost and Utilization Project) using physician-verified diagnoses and procedures readily available in MEPS.

\section{Analytic Approach}

Group comparisons were quantified with survey-weighted $\chi^{2}$. To assess demographic and clinical variability within the physicianpatient relationship subscale, we used standardized mean difference (SMD), an improvement over $P$ value with large sample sizes. ${ }^{31}$ To quantify the correlation between the physicianpatient relationship at baseline and functional health at follow up, we used the survey-weighted Pearson correlation. To assess the effect of 6 mutually exclusive physician-patient relationship trajectories on functional health, we relied on survey-weighted, covariate-adjusted predicted marginal means. To quantify the absolute size of the difference (controlling for sample size), 
we converted group differences to effect sizes with the Cohen d statistic. To assess for differences across the 6 trajectories, we used multiple pairwise comparisons with Tukey contrasts. Statistical analyses were conducted with $\mathrm{R}$ version 3.5.0 (the R Foundation) and the survey package.

\section{RESULTS}

\section{Demographic Characteristics}

Descriptively, adults with officebased physician visits in both 2015 and 2016 were on average aged 52.7 years ( $\mathrm{SD}=17.7$ years) and $59.4 \%$ female. Compared with adults with no visits in either year, and those with visits in one year but not the other, adults with office-based physician visits in both years differed clinically in age, age group distribution, sex, race/ethnicity, educational attainment, US region, multimorbidity, insurance status, and usual source of care (Table 1).

\section{Physician-Patient Relationship by Subgroup}

Physician-patient relationship scores varied by some, but not all, demographic and clinical characteristics. Adults with multimorbidity, defined as the presence of $\geq 5$ physician-diagnosed conditions, had a significantly lower score than those with $0-1$ condition $(66.28$ [95\% CI, 65.61-66.95] vs 71.38 [95\% CI, 69.13-73.63]; $\mathrm{SMD}=0.26)($ Table 2). Uninsured patients had a lower score than those with private insurance $(60.59$ [95\% CI, 57.49-63.69] vs 67.14 [95\% CI, 66.49-67.79]; $\mathrm{SMD}=0.33$ ). Those with low baseline functional health scored lower than those with high baseline health $(63.33$ [95\% CI, 62.45-64.21] vs 69.97 [95\% CI, 69.31-70.64] $\left.]_{i} \mathrm{SMD}=0.52\right)$.

\section{Physician-Patient Relationship and Functional Health}

The survey-weighted correlation between baseline physician-patient relationship (2015) and follow-up functional health $(2016)$ was $0.20(P<.001)$ (Supplemental Figure 2 https://www.AnnFamMed.org/ content/18/5/422/suppl/DC1/).

\section{Physician-Patient Relationship Trajectories and Functional Health}

Physician-patient relationship trajectories were associated with functional health when accounting for possible confounders in both 2015 and 2016. Regardless of patients' baseline classifications (high, low), improved relationship trajectories for the 2015-2016 interval were associated with improved functional health (effect estimate $[\mathrm{EE}]=0.08[95 \% \mathrm{CI}, 0.02-0.13]$ and $\mathrm{EE}=0.05$ [95\% CI, 0-0.10], respectively) (Table 3). Flat physician-patient relationship trajectories were associated with worsened functional health $(\mathrm{EE}=-0.11[95 \% \mathrm{CI}$, -0.21 to 0.02$]$ and $\mathrm{EE}=-0.10$ [95\% $\mathrm{CI},-0.21$ to 0.02 , respectively). Worsened physician-patient relationship trajectories were also associated with worsened functional health $(\mathrm{EE}=-0.33[95 \% \mathrm{CI},-0.47$ to -0.02$]$ and $\mathrm{EE}=-0.16[95 \% \mathrm{CI},-0.35$ to -0.03$]$, respectively). Three of the 15 multiple pairwise comparisons were significantly different (high $\rightarrow$ same vs high $\rightarrow$ better; high $\rightarrow$ worse vs high $\rightarrow$ better $_{i}$ and low $\rightarrow$ better vs high $\rightarrow$ worse, $P<.001$ ) (Supplemental Table 1, https:// www.AnnFamMed.org/content/18/5/422/supp1/DC1/). No significant difference was found between patients with flat trajectories (better, same, worse), irrespective of baseline score category.

\section{DISCUSSION}

Using nationally representative longitudinal data, we found empirical evidence that improved physicianpatient relationship trajectories were associated with improved functional health, whereas worsened relationship trajectories were associated with worsened functional health. These findings with individual-level data uphold findings from studies based on nationally representative and convenience samples. ${ }^{32-36}$

We expanded on prior longitudinal outcomes analyses of individual patients' experiences with care ${ }^{36}$ in 2 
ways, first by using a measure of physician-patient relationship with preliminary evidence of reliability and validity $^{23,24}$ and second by modeling additional patient heterogeneity via the use of 6 mutually exclusive time-trend trajectories. These findings provide datadriven evidence of the importance of relationship-centered care as one viable strategy to improve population health outcomes. ${ }^{10,37,38}$

Table 1. Demographic and Clinical Characteristics of US Community-Dwelling Adults, Comparing Patients With No Physician Office Visits (2015 or 2016), Patients With Physician Office Visits (2015 or 2016), and Patients With Physician Office Visits (2015 and 2016)

\begin{tabular}{|c|c|c|c|c|c|c|}
\hline & & $\begin{array}{c}\text { Overall, } \\
\text { US Adult } \\
\text { Population }\end{array}$ & $\begin{array}{l}\text { Patients With } \\
\text { No Office } \\
\text { Visits (2015 } \\
\text { or 2016) }\end{array}$ & $\begin{array}{c}\text { Patients } \\
\text { With Office } \\
\text { Visits (2015 } \\
\text { or 2016) }\end{array}$ & $\begin{array}{c}\text { Patients } \\
\text { With Office } \\
\text { Visits (2015 } \\
\text { and 2016) }\end{array}$ & \\
\hline $\begin{array}{l}\text { Baseline } \\
\text { Characteristic }\end{array}$ & $\begin{array}{c}\text { MEPS } \\
\text { Sample } \\
n=11,782\end{array}$ & $\begin{array}{l}\text { Weighted } \\
\text { Frequency (in } \\
1,000 \mathrm{~s})(\%) \\
\mathrm{N}=238,747 \\
(100 \%)\end{array}$ & $\begin{array}{c}\text { Weighted } \\
\text { Frequency (in } \\
1,000 \mathrm{~s})(\%) \\
\mathrm{N}_{1}=51,546 \\
(21.6 \%)\end{array}$ & $\begin{array}{c}\text { Weighted } \\
\text { Frequency (in } \\
1,000 \mathrm{~s})(\%) \\
\mathrm{N}_{2}=56,885 \\
(23.8 \%)\end{array}$ & $\begin{array}{c}\text { Weighted } \\
\text { Frequency (in } \\
1,000 \mathrm{~s})(\%) \\
\mathrm{N}_{3}=130,316 \\
(54.6 \%)\end{array}$ & $P$ Value \\
\hline Age, mean (SD) & $46.0(17.5)$ & $46.6(17.8)$ & $37.6(14.2)$ & $40.8(15.5)$ & $52.7(17.7)$ & $<.001$ \\
\hline Age group & & & & & & $<.001$ \\
\hline$<40 y$ & $4,707(40.0)$ & $93,301(39.1)$ & $30,487(59.1)$ & $29,532(51.9)$ & $33,282(25.5)$ & \\
\hline $40-64$ y & $5,107(43.3)$ & $102,195(42.8)$ & $19,112(37.1)$ & $22,924(40.3)$ & $60,159(46.2)$ & \\
\hline$\geq 65 y$ & $1,968(16.7)$ & $43,251(18.1)$ & $1,948(3.8)$ & $4,428(7.8)$ & $36,874(28.3)$ & \\
\hline Sex & & & & & & $<.001$ \\
\hline Male & $5,455(46.3)$ & $114,958(48.2)$ & $32,548(63.1)$ & $29,503(51.9)$ & $52,908(40.6)$ & \\
\hline Female & $6,327(53.7)$ & 123,789 (51.8) & 18,998 (36.9) & $27,382(48.1)$ & $77,408(59.4)$ & \\
\hline Race/Ethnicity & & & & & & $<.001$ \\
\hline White, non-Hispanic & $5,037(42.8)$ & $152,163(63.7)$ & $26,842(52.1)$ & $33,429(58.8)$ & 91,891 (70.5) & \\
\hline Black, non-Hispanic & $2,113(17.9)$ & $27,936(11.7)$ & $7,615(14.8)$ & $6,994(12.3)$ & $13,328(10.2)$ & \\
\hline Asian, non-Hispanic & $938(8.0)$ & $14,220(6.0)$ & $3,480(6.8)$ & $4,251(7.5)$ & $6,489(5.0)$ & \\
\hline Other, non-Hispanic & $312(2.6)$ & $6,972(2.9)$ & $1,296(2.5)$ & $1,397(2.5)$ & $4,279(3.3)$ & \\
\hline Hispanic & $3,382(28.7)$ & $37,456(15.7)$ & $12,314(23.9)$ & $10,813(19.0)$ & $14,328(11.0)$ & \\
\hline Education ${ }^{a}$ & & & & & & $<.001$ \\
\hline$<$ High school & 2,331 (19.8) & $30,476(12.8)$ & $8,417(16.3)$ & $6,978(12.3)$ & $15,080(11.6)$ & \\
\hline High school graduate & $3,729(31.6)$ & $73,042(30.6)$ & $18,186(35.3)$ & $17,879(31.4)$ & $36,977(28.4)$ & \\
\hline$>$ High school & $5,611(47.6)$ & $133,789(56.0)$ & $24,271(47.1)$ & $31,643(55.6)$ & $77,875(59.8)$ & \\
\hline US region & & & & & & .02 \\
\hline Northeast & $1,971(16.7)$ & $43,448(18.2)$ & $9,167(17.8)$ & $9,717(17.1)$ & $24,566(18.9)$ & \\
\hline Midwest & $2,242(19.0)$ & $50,597(21.2)$ & $10,290(20.0)$ & $11,451(20.1)$ & $28,856(22.1)$ & \\
\hline South & $4,410(37.4)$ & $88,295(37.0)$ & $19,456(37.7)$ & $20,431(35.9)$ & $48,408(37.1)$ & \\
\hline West & $3,159(26.8)$ & $56,406(23.6)$ & $12,634(24.5)$ & $15,286(26.9)$ & $28,487(21.9)$ & \\
\hline Multimorbidity ${ }^{a}$ & & & & & & $<.001$ \\
\hline 0-1 diagnosis & $1,945(16.5)$ & $38,428(16.1)$ & $12,736(24.7)$ & $14,661(25.8)$ & $11,032(8.7)$ & \\
\hline 2-4 diagnoses & $3,789(32.2)$ & $79,785(33.4)$ & $12,260(23.8)$ & $23,343(41.0)$ & $44,183(33.9)$ & \\
\hline$\geq 5$ diagnoses & $3,772(32.0)$ & $83,426(34.9)$ & $2,400(4.7)$ & $8,844(15.5)$ & $72,183(55.4)$ & \\
\hline Insurance & & & & & & $<.001$ \\
\hline Private & $6,968(59.1)$ & $168,343(70.5)$ & $31,780(61.7)$ & $42,118(74)$ & $94,445(72.5)$ & \\
\hline Public & $3,175(26.9)$ & $48,635(20.4)$ & $7,802(15.1)$ & $9,308(16.4)$ & $31,525(24.2)$ & \\
\hline Uninsured & 1,639 (13.9) & $21,769(9.1)$ & $11,964(23.2)$ & $5,459(9.6)$ & $4,346(3.3)$ & \\
\hline Usual source of care & $8,388(71.2)$ & $177,517(74.4)$ & $23,090(44.8)$ & $39,323(69.1)$ & $115,104(88.3)$ & $<.001$ \\
\hline $\begin{array}{l}\text { Physician-patient rela- } \\
\text { tionship, mean (SD) }\end{array}$ & $66.6(14.3)$ & $67.1(13.6)$ & $66.0(15.8)$ & $67.4(14.6)$ & $67.1(13.2)$ & .49 \\
\hline \multicolumn{7}{|c|}{$\mathrm{HC}=$ MEPS Household Component; MEPS = Medical Expenditure Panel Survey. } \\
\hline \multicolumn{7}{|c|}{$\begin{array}{l}\text { Notes: Data are presented as population count (in 1,000s) and percent unless otherwise noted. For MEPS sample, data are shown as count (\%), except for continuous } \\
\text { measures, which are presented as mean (SD). For physician-patient relationship, there are missing data for } n=5,342 . x^{2} \text { test performed on all observations with value }>0 \text {. }\end{array}$} \\
\hline \multicolumn{7}{|c|}{ Source: Agency for Healthcare Research and Quality, Medical Expenditure Panel Survey, Longitudinal Panel (HC-193, 2015-2016) and Medical Conditions (HC-190, 2015). } \\
\hline a Data missing for education & $=111)$, multimorbidi & $=2,276)$, and usual & rce of care $(n=3,394$ & & & \\
\hline
\end{tabular}


Relationship-centered care might be especially important among aging adults with a disproportionate burden of chronic diseases, who represent a growing subpopulation in the United States. In the bivariate analysis, we found evidence that adults with $\geq 5$ diagnosed conditions reported physician-patient relationships that were significantly lower in quality than those reported by adults without multimorbidity. This discrepancy might reflect unmet physician-patient relationship needs among adults bearing multimorbidity burdens and therefore signal an opportunity for intervention. ${ }^{39}$

The present study has several limitations. Despite controlling for known confounders, patients who report high-quality physician-patient relationship scores might differ in ways that are not observable in the data (eg, in health or in attitudes to self/life). Whereas MEPS is a rich data source, measures on personal agency and attitudes are not presently available. It is also possible that the associations observed are due in part to a spurious association as a result of the MEPS self-administered questionnaire format. Ten of $14(71 \%)$ of the items in MEPS-PC originate from a single survey instrument (SF-12). However, our longitudinal approach, coupled with the construction of 6 mutually exclusive trajectories, addresses such possible bias. Some might argue that the 1-year effect estimates are unimportant. ${ }^{40}$ However, these effect estimates need to be considered within the proper context, especially in light of the single-year follow up. The practical importance of any effect depends both on relative costs and overall benefits. ${ }^{41}$ From a population health perspective, with $86 \%$ of Americans having access to a usual source of care and the majority listing a doctor's office as the usual place they receive care, ${ }_{1}^{42}$ these small 1 -year effects could accumulate to clinically relevant improvements with longer follow up. ${ }^{43}$ Finally, it is important to note that the MEPS-PC Relationship measure does not quantify patient experiences with a specific physician but rather with the overall physician care team. Many patients, especially those with complex conditions, visit multiple physicians in a given year and undoubtedly encounter a range of physician-patient relationship qualities. At present, MEPS unfortunately does not allow analysis of individual physician encounters.

The present observational study brings forward new questions answerable via the Agency for Healthcare Research and Quality's publicly available MEPS data. Among the 14 items comprising the MEPS-PC subscale, is any one or combination of physician behaviors more important in improving patients' selfreported health outcomes? What are the chief drivers that lead to improved physician-patient relationships? For example, are such improvements driven by changes in a patient's employer-provided health insurance as a

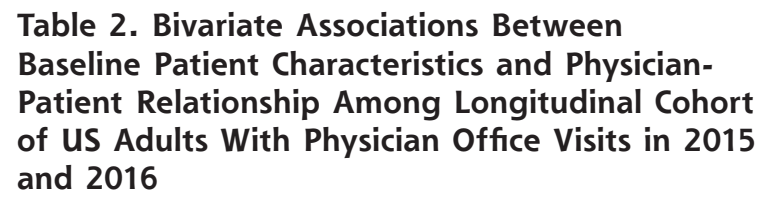

\begin{tabular}{|c|c|c|}
\hline \multirow[b]{2}{*}{$\begin{array}{l}\text { Baseline } \\
\text { Characteristic }\end{array}$} & \multicolumn{2}{|c|}{$\begin{array}{l}\text { Physician-Patient } \\
\text { Relationship Score }\end{array}$} \\
\hline & $\begin{array}{l}\text { Survey-Weighted } \\
\text { Population Mean } \\
\qquad(95 \% \mathrm{Cl})\end{array}$ & SMDa \\
\hline Age group & & 0.14 \\
\hline$<40$ y & $65.85(64.63-67.07)$ & \\
\hline $40-64$ y & $66.31(65.47-67.15)$ & \\
\hline$\geq 65 y$ & $68.65(67.77-69.53)$ & \\
\hline Sex & & 0.01 \\
\hline Male & $66.95(66.15-67.75)$ & \\
\hline Female & $67.02(66.31-67.73)$ & \\
\hline Race/Ethnicity & & 0.17 \\
\hline White, non-Hispanic & $67.10(66.43-67.77)$ & \\
\hline Black, non-Hispanic & $68.39(67.06-69.72)$ & \\
\hline Asian, non-Hispanic & $66.62(64.41-68.83)$ & \\
\hline Other, non-Hispanic & $62.68(58.37-65.99)$ & \\
\hline Hispanic & $66.33(64.78-67.88)$ & \\
\hline Education & & 0.02 \\
\hline$<$ High school & $67.08(65.53-68.63)$ & \\
\hline High school graduate & $67.24(66.26-68.22)$ & \\
\hline$>$ High school & $66.88(66.17-67.59)$ & \\
\hline US region & & 0.10 \\
\hline Northeast & $68.06(66.75-69.37)$ & \\
\hline Midwest & $67.71(66.59-68.83)$ & \\
\hline South & $66.72(65.86-67.58)$ & \\
\hline West & $65.85(64.56-67.14)$ & \\
\hline Multimorbidity & & 0.26 \\
\hline 0-1 diagnosis & $71.38(69.13-73.63)$ & \\
\hline 2-4 diagnoses & $67.65(66.67-68.63)$ & \\
\hline$\geq 5$ diagnoses & $66.28(65.61-66.95)$ & \\
\hline Insurance & & 0.33 \\
\hline Private & $67.14(66.49-67.79)$ & \\
\hline Public & $67.31(66.29-68.33)$ & \\
\hline Uninsured & 60.59 (57.49-63.69) & \\
\hline Baseline functional health ${ }^{b}$ & & 0.52 \\
\hline Low & $63.33(62.45-64.21)$ & \\
\hline High & $69.97(69.31-70.64)$ & \\
\hline \multicolumn{3}{|c|}{$\begin{array}{l}\mathrm{HC}=\text { MEPS Household Component; SF-12 = 12-Item Short-Form Survey; } \\
\mathrm{SMD}=\text { standardized mean difference. }\end{array}$} \\
\hline \multicolumn{3}{|c|}{$\begin{array}{l}\text { Note: Population mean and } 95 \% \text { Cl of physician-patient relationship score } \\
\text { among adults } \geq 18 \text { years with office visits in } 2015 \text { and } 2016 \text {, reflective of } 83 \\
\text { million patients in } 2015 \text {. }\end{array}$} \\
\hline \multicolumn{3}{|c|}{$\begin{array}{l}\text { Source: Agency for Healthcare Research and Quality, Medical Expenditure } \\
\text { Panel Survey, Longitudinal Panel (HC-193, 2015-2016) and Medical Conditions } \\
\text { (HC-190, 2015). }\end{array}$} \\
\hline \multicolumn{3}{|c|}{$\begin{array}{l}\text { a SMD between the } 2 \text { extremes in each category. Difference in means or } \\
\text { proportions divided by SD; imbalance defined as absolute value }>0.2 \text { (small } \\
\text { effect size). } \\
\text { b Functional health captured with the SF-12 instrument, cut at the population } \\
\text { median. }\end{array}$} \\
\hline
\end{tabular}


Table 3. Effect of Physician-Patient Relationship Change Trajectories on Functional Health Using Survey-Weighted, Covariate-Adjusted, Predicted Marginal Means Among a National Representative Cohort of US Adults With Office Visits in 2 Consecutive Years $(n=3,645$, Representative of 83 Million US Adults), 2015-2016

\begin{tabular}{|c|c|c|c|c|c|c|c|}
\hline \multirow[b]{2}{*}{ Relationship } & \multirow[b]{2}{*}{$\begin{array}{l}\text { MEPS } \\
\text { Cohort } n\end{array}$} & \multicolumn{4}{|c|}{ Functional Health (SF-12) } & \multicolumn{2}{|c|}{ Cohen Effect Estimate } \\
\hline & & $\begin{array}{c}2015 \\
\text { Mean (SD) }\end{array}$ & $\begin{array}{c}2016 \\
\text { Mean (SD) }\end{array}$ & $\begin{array}{l}\text { Change } \\
\text { Mean (SD) }\end{array}$ & $95 \% \mathrm{Cl}$ & $\begin{array}{c}\text { Effect } \\
\text { Estimate }\end{array}$ & $95 \% \mathrm{Cl}$ \\
\hline High $\longrightarrow$ Better & 1,208 & $97.90(0.58)$ & $98.94(0.60)$ & $1.04(0.39)$ & 0.29 to 1.80 & 0.08 & 0.02 to 0.13 \\
\hline High $\longrightarrow$ Same & 444 & $96.33(0.83)$ & $94.82(0.85)$ & $-1.51(0.64)$ & -2.76 to -0.27 & -0.11 & -0.21 to 0.02 \\
\hline High $\rightarrow$ Worse & 197 & $93.68(1.58)$ & $89.62(1.49)$ & $-4.06(0.88)$ & -5.78 to -2.32 & -0.33 & -0.47 to -0.02 \\
\hline Low $\longrightarrow$ Better & 1,397 & $97.89(0.62)$ & $98.75(0.61)$ & $0.86(0.46)$ & -0.04 to 1.76 & 0.05 & 0 to 0.10 \\
\hline Low $\rightarrow$ Same & 293 & $95.22(0.99)$ & $93.90(1.12)$ & $-1.32(0.78)$ & -2.85 to 0.21 & -0.10 & -0.21 to 0.02 \\
\hline Low $\rightarrow$ Worse & 106 & $93.82(1.66)$ & $91.39(2.03)$ & $-2.43(1.48)$ & -5.33 to -0.47 & -0.16 & -0.35 to -0.03 \\
\hline
\end{tabular}

HC = MEPS Household Component; MEPS = Medical Expenditure Panel Survey; MEPS-PC = MEPS Primary Care measure; SF-12 = 12-Item Short-Form Survey; US = United States.

Notes: Mean response for each factor, adjusted for all known confounders, including age, sex, race/ethnicity, educational attainment, insurance status, multimorbidity, and US region using survey-weighted predicted marginal means. Relationship is operationalized using the MEPS-PC Relationship composite measure and cut into 6 trajectories based on 2015 score (high or low) and 2016 score (better, same, worse). High Relationship score in 2015 denotes $\geq$ median Relationship score at baseline (69.23), whereas Low Relationship score denotes < the population median Relationship score at baseline. Better in 2016 reflects a 1-year change in Relationship score $\geq 0.5$ SD; Worse reflects a 1-year change greater than -0.5 SD, and change in either direction < 0.5 SD d enotes Same. The SD for Relationship in 2015 was 13.35 . Statistical difference between 3 of 15 pairwise comparisons using Tukey pairwise multiple comparison procedures $(P=.05$, not adjusted for multiple testing [Bonferroni]): High $\rightarrow$ Same and High $\rightarrow$ Better, High $\rightarrow$ Worse and High $\rightarrow$ Better, Low $\rightarrow$ Better and Low $\rightarrow$ Worse. Borderline significance $(P<.10)$ for High $\rightarrow$ Worse and High $\rightarrow$ Same, Low $\rightarrow$ Better and High $\rightarrow$ Same, Low $\rightarrow$ Same and Low $\rightarrow$ Better.

Source: Agency for Healthcare Research and Quality, Medical Expenditure Panel Survey, Longitudinal Panel (HC-193, 2015-2016) and Medical Conditions (HC-190, 2015).

consequence of change in employment? Investigators might also wish to assess whether the quality of the physician-patient relationship differs by physician specialty or type of office visit. These important questions and others are ready to be addressed with new data from MEPS released each September.

\section{CONCLUSION}

Using nationally representative data, longitudinal analysis suggests that the quality of the physician-patient relationship is positively associated with functional health. These findings might inform health care strategies and health policy aimed at improving patientcentered health outcomes.

To read or post commentaries in response to this article, see it online at https://www.AnnFamMed.org/content/18/5/422.

Key words: United States; primary care; functional health; relationship; impact; Medical Expenditure Panel Survey

Submitted August 4, 2019; submitted, revised, November 25, 2019; accepted January 27, 2020.

ORCID ID: https://orcid.org/0000-0002-3673-1599

Disclosure: This analysis was completed while the lead author was a $\mathrm{PhD}$ candidate at Case Western Reserve University. He is now a statistician with Substance Abuse and Mental Health Services and the Center for Behavioral Health Statistics and Quality. Dr Stange was supported as a Scholar of The Institute for Integrative Health and as an American Cancer Society Clinical Research Professor. There are no other disclosures of funding or disclosures of potential conflict of interest to report.
Acknowledgments: Preliminary results of this work were presented at the 2018 American Public Health Association annual meeting. We thank Dr Mary Assad for editing expertise. We also thank the deputy editor, Dr Diane M. Harper, and the 3 peer reviewers for substantive suggestions that enhanced the content and clarity of this manuscript.

Supplementary materials: Available at https://www. AnnFamMed.org/content/18/5/422/suppl/DC1/.

\section{References}

1. Starfield B, Shi L, Macinko J. Contribution of primary care to health systems and health. Milbank Q. 2005;83(3):457-502.

2. Macinko J, Starfield B, Shi L. The contribution of primary care systems to health outcomes within Organization for Economic Cooperation and Development (OECD) countries, 1970-1998. Health Serv Res. 2003;38(3):831-865.

3. Macinko J, Starfield B, Shi L. Quantifying the health benefits of primary care physician supply in the United States. Int J Health Serv. 2007;37(1):111-126.

4. Shi L, Starfield B, Politzer R, Regan J. Primary care, self-rated health, and reductions in social disparities in health. Health Serv Res. 2002;37(3):529-550.

5. Kim MY, Kim JH, Choi IK, Hwang IH, Kim SY. Effects of having usual source of care on preventive services and chronic disease control: a systematic review. Korean J Fam Med. 2012;33(6):336-345.

6. Sommers BD, Maylone B, Blendon RJ, Orav EJ, Epstein AM. Threeyear impacts of the Affordable Care Act: improved medical care and health among low-income adults. Health Aff (Millwood). 2017; 36(6):1119-1128.

7. Stewart MA. Effective physician-patient communication and health outcomes: a review. CMAJ. 1995;152(9):1423-1433.

8. Safran DG. Defining the future of primary care: what can we learn from patients? Ann Intern Med. 2003;138(3):248-255. 
9. Baker R, Mainous AG III, Gray DP, Love MM. Exploration of the relationship between continuity, trust in regular doctors and patient satisfaction with consultations with family doctors. Scand J Prim Health Care. 2003;21(1):27-32.

10. Frankel RM. Relationship-centered care and the patient-physician relationship. J Gen Intern Med. 2004;19(11):1163-1165.

11. McWhinney IR, Freeman T. Textbook of Family Medicine. $3^{\text {rd }}$ ed. Oxford University Press; 2009.

12. Stange KC. A science of connectedness. Ann Fam Med. 2009;7(5): 387-395.

13. O'Malley AS, Rich EC, Maccarone A, DesRoches CM, Reid RJ. Disentangling the linkage of primary care features to patient outcomes: a review of current literature, data sources, and measurement needs. J Gen Intern Med. 2015;30 Suppl 3 (Suppl 3):S576-S585.

14. Safran DG, Taira DA, Rogers WH, Kosinski M, Ware JE, Tarlov AR. Linking primary care performance to outcomes of care. J Fam Pract. 1998;47(3):213-220.

15. Stange KC, Etz RS, Gullett $H$, et al. Metrics for assessing improvements in primary health care. Annu Rev Public Health. 2014;35: 423-442.

16. Smith SM, Soubhi H, Fortin M, Hudon C, O'Dowd T. Interventions for improving outcomes in patients with multimorbidity in primary care and community settings. Cochrane Database Syst Rev. 2012;4: CD006560.

17. Shortell SM, Poon BY, Ramsay PP, et al. A multilevel analysis of patient engagement and patient-reported outcomes in primary care practices of accountable care organizations. J Gen Intern Med. 2017; 32(6):640-647.

18. Flocke SA. Measuring attributes of primary care: development of a new instrument. J Fam Pract. 1997;45(1):64-74.

19. Safran DG, Kosinski M, Tarlov AR, et al. The Primary Care Assessment Survey: tests of data quality and measurement performance. Med Care. 1998;36(5):728-739.

20. Shi L, Starfield B, Xu J. Validating the adult Primary Care Assessment Tool. J Fam Pract. 2001;50(2):161-175.

21. Van der Feltz-Cornelis CM, Van Oppen P, Van Marwijk HW, De Beurs E, Van Dyck R. A patient-doctor relationship questionnaire (PDRQ-9) in primary care: development and psychometric evaluation. Gen Hosp Psychiatry. 2004;26(2):115-120.

22. Cohen SB. Design strategies and innovations in the Medical Expenditure Panel Survey. Med Care. 2003;41(7 Suppl):III5-III12.

23. Olaisen RH, Flocke SA, Smyth KA, Schluchter MD, Koroukian SM, Stange KC. Developing a new measure of primary care using the Medical Expenditure Panel Survey. Med Care. 2019;57(6):475-481.

24. Olaisen RH, Flocke SA, Smyth KA, Schluchter MD, Koroukian SM, Stange, KC. Validating the new primary care measure in the Medical Expenditure Panel Survey. Med Care. 2020;58(1):52-58.

25. Agency for Healthcare Research and Quality. Medical Expenditure Panel Survey (MEPS). https://www.meps.ahrq.gov/mepsweb/. Accessed Nov 22, 2019.

26. von Elm E, Altman DG, Egger M, Pocock SJ, Gøtzsche PC, Vandenbroucke JP; STROBE Initiative. The Strengthening the Reporting of Observational Studies in Epidemiology (STROBE) statement: guidelines for reporting observational studies. Ann Intern Med. 2007; $147(8): 573-577$.
27. Shrier I, Platt RW. Reducing bias through directed acyclic graphs. BMC Med Res Methodol. 2008;8:70.

28. Ware J Jr, Kosinski M, Keller SD. A 12-Item Short-Form Health Survey: construction of scales and preliminary tests of reliability and validity. Med Care. 1996;34(3):220-233.

29. Cheak-Zamora NC, Wyrwich KW, McBride TD. Reliability and validity of the SF-12v2 in the Medical Expenditure Panel Survey. Qual Life Res. 2009;18(6):727-735.

30. Norman GR, Sloan JA, Wyrwich KW. Interpretation of changes in health-related quality of life: the remarkable universality of half a standard deviation. Med Care. 2003;41(5):582-592.

31. Yang DS, Dalton JE. A unified approach to measuring the effect size between two groups using SAS. SAS Global Forum. 2012;335:1-6.

32. Shi L, Green LH, Kazakova S. Primary care experience and racial disparities in self-reported health status. J Am Board Fam Pract. 2004; $17(6): 443-452$.

33. Saultz JW, Lochner J. Interpersonal continuity of care and care outcomes: a critical review. Ann Fam Med. 2005;3(2):159-166.

34. Bazemore A, Petterson S, Peterson LE, Bruno R, Chung Y, Phillips RL Jr. Higher primary care physician continuity is associated with lower costs and hospitalizations. Ann Fam Med. 2018;16(6):492-497.

35. Etz RS, Zyzanski SJ, Gonzalez MM, Reves SR, O'Neal JP, Stange KC. A new comprehensive measure of high-value aspects of primary care. Ann Fam Med. 2019;17(3):221-230.

36. Xu X, Buta E, Anhang Price R, Elliott MN, Hays RD, Cleary PD. Methodological considerations when studying the association between patient-reported care experiences and mortality. Health Serv Res. 2015;50(4):1146-1161.

37. Beach MC, Inui T; Relationship-Centered Care Research Network. Relationship-centered care. A constructive reframing. J Gen Intern Med. 2006;21(Suppl 1):S3-S8.

38. Epstein RM, Fiscella K, Lesser CS, Stange KC. Why the nation needs a policy push on patient-centered health care. Health Aff (Millwood). 2010;29(8):1489-1495.

39. World Health Organization. Preparing a health care workforce for the 21st century: the challenge of chronic conditions. https://apps.who. int/iris/handle/10665/43044/. Published 2005. Accessed Aug 2, 2019.

40. Fritz CO, Morris PE, Richler JJ. Effect size estimates: current use, calculations, and interpretation. J Exp Psychol Gen. 2012;141(1):2-18.

41. Hojat M, Xu G. A visitor's guide to effect sizes: statistical significance versus practical (clinical) importance of research findings. Adv Health Sci Educ Theory Pract. 2004;9(3):241-249.

42. Ashman JJ, Rui P, Okeyode T; Centers for Disease Control and Prevention; National Center for Health Statistics. Characteristics of office-based physician visits, 2016. NCHS Data Brief No. 331. https://www.cdc.gov/nchs/products/databriefs/db331.htm. Published Jan 2019; Accessed Jul 13, 2020.

43. Coe R. It's the effect size, stupid: what "effect size" is and why it is important. Paper presented at the Annual Conference of the British Educational Research Association, University of Exeter, England, September 12-14, 2002. https://www.leeds.ac.uk/educol/ documents/00002182.htm. Accessed Jul 13, 2020. 